\title{
Sobre el potencial teórico de las representaciones sociales en el campo de la comunicación
}

En este artículo se desarrollan algunas reflexiones teóricas y metodológicas sobre cómo la teoría de las representaciones sociales podría ser utilizada en el campo de los estudios sobre comunicación. Se discuten algunas aplicaciones posibles de conceptos y premisas teóricas básicas de dicho modelo para comprender los procesos comunicacionales de producción de sentido, tanto en sus manifestaciones cotidianas como mediáticas. Especialmente, se destacan algunas ventajas de la teoría para orientar investigaciones sobre los mensajes mediáticos, identificando insumos para reconocer la organización holística y jerárquica de los significados que circulan en dicha clase de productos culturales.

PALABRAS CLAVE: representaciones sociales, medios de comunicación, teoría.
The article expounds on some theoretical and methodological reflections about how the theory of social representations may be used in the field of communication studies. It discusses some possible applications of theoretical concepts and basic assumptions of the model to understand the communication processes of production of meaning as much in their daily demonstrations as in the mass media. It especially highlights some advantages of the theory to guide research on media messages, identifying inputs to recognize the holistic and hierarchical organization of the meanings that circulate in this kind of cultural product.

KEY WORDS: social representations, media, theory.

1 Universidad de Guadalajara, México.

Correo electrónico: tania.rodriguez@csh.udg.mx 


\section{INTRODUCCIÓN}

La noción de comunicación ha sido tema de discusión a lo largo del vasto desarrollo de la teoría de las representaciones sociales (RS), aunque no ha sido un tema prioritario en la investigación empírica. No obstante, es posible identificar un creciente interés por establecer vínculos entre el estudio de las RS y la comunicación. En Europa, por ejemplo, Farr (1986), Doise (1991; 1993), Rouquette (1996), Wagner y Elejabarrieta (1994), Wagner y Hayes (2005), entre otros, han insistido en la importancia teórica de estudiar las RS considerando los medios de comunicación y, con esto, alcanzar un nivel de análisis colectivo. Annamaría de Rosa (2001a, 2006), por su parte, ha realizado investigaciones sobre representaciones sociales y comunicación mediática (publicidad, Internet), al mismo tiempo que ha impulsado la inclusión de estos temas en las últimas conferencias internacionales sobre representaciones sociales. En la región latinoamericana, también a manera de ejemplos, podemos identificar los trabajos de Gutiérrez (2006), Valencia (2007), García (2004), que promueven la vinculación del estudio de las RS con el análisis del discurso o retoman los postulados de Moscovici sobre los sistemas de comunicación mediática.

Como parte de estos esfuerzos por mostrar que el concepto y la teoría de RS son pertinentes para estudiar la comunicación como producción de sentido, tanto en sus manifestaciones mediáticas como cotidianas, ${ }^{2}$ este artículo tiene como objetivo principal indagar, a partir de la revisión de literatura relevante, algunas posibilidades de uso de

2 Desde el campo de los estudios de la comunicación, Fuentes (2003: 199) enfatiza el carácter sociocultural de los procesos comunicacionales, integrando conceptos y premisas teóricas que destacan "los procesos subjetivos e intersubjetivos de significación, a través de los esquemas preceptuales e interpretativos que en cada sector cultural median, y de las relaciones posibles con las estructuras y los sistemas objetivos de procesamiento y difusión de la información (...)”. Esta forma de comprender la comunicación, en mi opinión, es ampliamente compatible con la teoría de las RS. 
la teoría de las RS en la investigación en comunicación. De manera particular, se trata de explorar el potencial de tal teoría para estudiar mensajes o contenidos transmitidos por los medios de comunicación; de valorar si una teoría creada en la psicología social para estudiar el conocimiento ingenuo, esto es, las formas en que los individuos y los grupos sociales construimos ideas e imágenes sobre distintos objetos sociales a través de procesos comunicativos, puede servir para estudiar productos mediáticos.

Mi interés en hacer esta valoración surge de que, con frecuencia, estudiantes de licenciatura y posgrado en ciencias sociales se sienten atraídos por la teoría de las RS para estudiar las formas en que un medio de comunicación -la prensa, la radio, la televisión, la Internet, etc.- "representan" ciertos objetos o grupos sociales. Cuando leen las definiciones identifican las funciones; cuando notan que se habla de iconos o imágenes se entusiasman, pero comienzan a decepcionarse cuando se dan cuenta que la mayor parte de estudios empíricos sobre RS versan sobre cómo cierto grupo social representa un objeto específico y, en sus investigaciones sobre mensajes, resulta difícil identificar cuál es el grupo que está detrás de las representaciones mediáticas. Asimismo, se dan cuentan que bajo esta teoría se ha dado más importancia a los aspectos discursivos que a las imágenes en sentido estricto del término, es decir, a las imágenes con soporte material. Otro momento de duda surge cuando descubren que los métodos más utilizados de recolección y análisis de datos provienen precisamente de asociaciones de palabras, cuestionarios o entrevistas con personas, y que en menor medida se analizan documentos, imágenes o contenidos mediáticos, aunque hay varias excepciones.

Sin embargo, las aplicaciones típicas de la teoría no deberían ser un impedimento para adoptar ciertos aspectos o ciertas partes de la misma, que resultan reveladores para comprender cómo se organiza el conocimiento de sentido común que circula no sólo en las interacciones cotidianas, sino también por canales más poderosos de difusión e influencia, como los medios de comunicación.

La noción de representaciones sociales podría servir parar ampliar el espectro de las estructuras de conocimiento con las que se divulgan 
sentidos sobre los grupos y los objetos sociales, trascendiendo los usos típicos de las nociones de sesgos y estereotipos. ${ }^{3}$ Pero antes de seguir esta discusión es necesario describir brevemente de qué trata esta teoría, focalizando la atención en aquellos conceptos y premisas teóricas que considero potencialmente relevantes para los estudios en el campo de la comunicación.

\section{LA TEORÍA DE LAS REPRESENTACIONES SOCIALES}

Originalmente formulada por Moscovici (1979 [1961]), esta teoría llama la atención sobre la complejidad del pensamiento de sentido común, abre la posibilidad de estudiar cómo distintas cogniciones y creencias culturales se organizan jerárquicamente para comprender un objeto en un grupo social dado, y destaca los procesos sociales de comunicación y discurso en que surgen, se afianzan y se transforman. Como teoría, trata problemas que conciernen también a otros marcos teóricos y tradiciones de investigación: los conceptos de cultura, estructuras mediadoras, sentido común, conocimiento ordinario, habitus, cognición compartida, modelos culturales, son algunas categorías con las que el fenómeno que llamamos RS tiene puntos importantes de convergencia, aunque, por supuesto, también hay notables divergencias. Sin embargo, adentrarse en esas semejanzas y diferencias escapa a los propósitos de este artículo. Pero veamos cómo se definen.

La más clara la ofrece Denise Jodelet, figura relevante en este campo de estudio:

En tanto que fenómenos, las representaciones sociales se presentan bajo formas variadas, más o menos complejas. Imágenes que condensan un conjunto

3 En el campo de la comunicación, los mensajes mediáticos han sido estudiados en la investigación anglosajona clásica, sobre todo a partir de nociones como sesgos y estereotipos, conceptos que son sumamente limitados y han suscitado múltiples críticas (Giles, 2003; Williams, 2003). Esto ha impulsado el desarrollo de investigaciones sobre los mensajes desde otros paradigmas teóricos y metodológicos, como la semiótica, el análisis del discurso, las narrativas, etc. 
de significados; sistemas de referencia que nos permiten interpretar lo que sucede, e incluso, dar un sentido a lo inesperado; categorías que sirven para clasificar las circunstancias, los fenómenos y a los individuos con quienes tenemos algo que ver; teorías que permiten establecer hechos sobre ellos. Y a menudo, cuando se les comprende dentro de la realidad concreta de nuestra vida social, las representaciones sociales son todo ello junto (1986:472).

Dicho de otra manera, la Teoría de las RS estudia "la manera como grupos sociales (o en una escala más amplia, sociedades o culturas) conceptualizan un objeto material o simbólico", al mismo tiempo que analiza las diferencias manifiestas en esos sistemas de conceptualización dentro de un grupo o entre grupos sociales (Moscovici, 1988:641). ${ }^{4} \mathrm{La}$ idea de RS se refiere al sistema holístico, organizado, de ideas, creencias, imágenes, actitudes que se elaboran en torno a un objeto social relevante dentro de un grupo social. Por eso se habla en singular. Sin embargo, es posible hablar de RS en plural para indicar modos distintos de pensar los objetos sociales, divergencias o controversias en las formas de interpretarlos entre distintos grupos sociales.

Las RS son entendidas como modalidades del pensamiento de sentido común que se generan, permanecen y transforman mediante procesos comunicativos cotidianos y mediáticos (Moscovici, 1979 [1961]; Farr, 1986). Moscovici escribe: "La fórmula es corta: no hay representación sin comunicación y no hay comunicación sin divergencia". ${ }^{5}$ Se asume que la comunicación, sustentada por un fondo sociocultural compartido, es el medio a través del cuál los actores sociales adquieren competencias prácticas que les permiten reducir incertidumbres, asimilar las innovaciones, hacer familiar lo extraño y moverse con naturalidad en el

4 El lector debe tomar en cuenta que existen diversos modelos teóricos y metodológicos para el estudio de las RS (para una breve discusión sobre esto, ver Rodríguez, 2007).

5 "The formula is short: no representation without communication and no communication without divergence, concurrent representations, that is, without social stake. Of course the idea of conflict, of something at stake, does not play a great part, so it seems to me, in what we can read about social construction." (Moscovici, 1997). 
mundo. En este sentido, las RS, como pensamiento de sentido común, son distintas de las representaciones expertas o especializadas, sean científicas, religiosas o políticas. En opinión de Moscovici (2001:20) "podemos crear representaciones en orden de hacer familiar lo extraño, perturbante o asombroso." Lo extraño se refiere a cualquier experiencia que no encaja con las expectativas de un grupo social, previamente establecidas, como las cosas incongruentes, lo inusual, los milagros de la ciencia, las catástrofes naturales o las creaciones de los artistas y novelistas (Moscovici 2003 [1988]).

Las RS constituyen un tipo especial de estructura de significación relevante en el pensamiento de sentido común. El modelo clásico de Moscovici contempla tres componentes principales: información, actitud, y campo de representación, aunque en el desarrollo actual de la teoría se acepta una gran variedad de formas y componentes. En una representación social entran en juego actitudes, opiniones, esquemas, creencias, valores, metáforas, informaciones e imágenes que le dan cuerpo y estructura. Sin embargo, como señala Ibañez (1988), es importante tener en cuenta que la representación social no es "un cajón donde se amontonan elementos dispares y más o menos inconexos" sino que es una "unidad funcional, fuertemente organizada". La siguiente definición de Moscovici (1988: 220) destaca las interconexiones entre los componentes de una representación cuando la define como:

Una red de conceptos e imágenes interactuantes cuyos contenidos evolucionan continuamente a través del tiempo y el espacio. Cómo evolucione la red depende de la complejidad y velocidad de las comunicaciones como de la comunicación mediática disponible.

El concepto de RS ha sido interpretado por algunos autores en términos consensuales. Sin embargo, Moscovici puntualiza que la estructura de las representaciones permite la presencia simultánea de conceptos divergentes, ideas inconsistentes y significados paradójicos. De manera textual plantea que:

Las representaciones asumen una configuración donde conceptos e imágenes pueden coexistir sin exigir uniformidad, donde la incertidumbre y los malen- 
tendidos son tolerados para que la discusión pueda seguir y los pensamientos circular (Moscovici, 1988: 233).

En este sentido es que podemos considerar que el campo representacional es susceptible de contradicciones, fragmentaciones, negociación y debate. No obstante, esto no implica que no haya un terreno común histórico de significados compartidos que permiten a las personas discutir y negociar.

Como he hecho aquí, cuando se quiere esclarecer el significado de un concepto teórico, lo usual es citar las definiciones clásicas para limitar los contornos de aquello a lo que hace referencia. Sin embargo, casi nunca se aclara qué es lo que no se está estudiando, qué parte de la realidad queda excluida con el recorte conceptual implicado en las RS. Esto sucede a pesar de los intentos para delimitar cuándo un objeto es realmente un objeto de RS o para distinguirlas de otras cogniciones con las cuales se identifica o confunde. Cuando se señala que las RS son una modalidad del pensamiento de sentido común, se asume que existen otras modalidades como los esquemas, las actitudes, los estereotipos, los prototipos u otras clases de estructuras cognitivas, siempre y cuando actúen de manera aislada y no sean elementos fundamentales de la integración o identidad de un grupo social o comunidad cultural. Wagner y Elejabarrieta (1997:829) utilizan un ejemplo divertido e interesante para contrastar el tipo de conocimiento que implica las RS. Estos autores se preguntan si existe una representación social de las espinacas, considerando que las personas tienen actitudes hacia ellas (a algunos les gustan y a otros no), producen prácticas (algunos las pedirán en los restaurantes y otros no), asocian conocimientos (las espinacas tienen vitaminas, son nutritivas), han sido símbolo mediático en la caricatura "Popeye". Sin embargo, su conclusión es que a pesar de que las espinacas sean un objeto de conocimiento cotidiano (generan actitudes, conocimientos, prácticas y símbolos) no pueden considerarse objeto de RS porque no emergen de una experiencia grupal o social relevante, esto es, porque ningún grupo social se puede asociar a partir de compartir conocimientos cotidianos sobre las espinacas y porque el conocimiento de estas no está revestido de transformaciones simbólicas para hacerlas comprensibles en la vida cotidiana. 


\section{LAS CONDICIONES DE EMERGENCIA \\ DE UNA REPRESENTACIÓN SOCIAL}

En este sentido, es importante tener en cuenta que no todo objeto social es un objeto de RS. Algunos autores se han enfocado en identificar aquellas propiedades o características que son necesarias para pensar que un objeto social es generador de RS. Originalmente, Moscovici propuso que para considerar a un objeto como el de una representación social debían cumplirse, al menos, tres condiciones: a) la dispersión de las informaciones (p. ej. la existencia de múltiples debates mediáticos); b) la compulsión a la inferencia, en el sentido de una presión por desarrollar comportamientos y discursos frente a objetos que se conocen poco; y c) la focalización selectiva de grupos e individuos, en la medida en que su ubicación determinará el interés o desinterés por ciertos aspectos del objeto (ver Moscocivi, 1979[1961], 1986). Más adelante, Pascal Moliner (1996) puntualizó seis condiciones favorables para la emergencia de una representación social:

1. Los objetos favorables para generar una RS deben ser polimorfos, esto es, aparecer de diferentes formas en nuestra sociedad y permitir el interjuego entre los grupos sociales involucrados en su definición.

2. La existencia de una RS depende de la existencia de un grupo, sea este estructural o coyuntural. De modo que la emergencia de una RS implica intercambios entre personas que comparten preocupaciones o prácticas hacia un objeto social.

3. Para que emerja una RS se requiere una coyuntura en la que grupos preexistentes se encuentran confrontados a un objeto nuevo y problemático

4. Los interjuegos sociales que pueden originar una RS son la identidad y la cohesión social.

5. La dinámica social es un elemento importante para la emergencia de una RS, en la medida en que "toda representación se forma con relación a otro". Esto implica analizar las relaciones que mantiene el grupo frente a un objeto, con respecto a las relaciones que otros grupos sociales tienen frente al mismo. 
6. La ausencia de ortodoxia es otra condición para la emergencia de una RS, pues cuando un grupo está sujeto a instancias de control y de regulación de la actividad de sus miembros en un marco deontológico muy preciso, se impide la construcción de RS.

De manera que todo estudio de RS deberá preguntarse si el objeto de representación estudiado suele suscitar apreciaciones diferentes, de qué dependerían tales apreciaciones, qué tan abundante o escasa es la información que circula en los grupos estudiados sobre el objeto de representación, y en qué medida y bajo qué condiciones o coyunturas se ha vuelto un objeto de discusión pública.

\section{LA OBJETIVACIÓN Y EL ANCLAJE}

Los teóricos de las RS suelen admitir que los mecanismos que intervienen en la creación y el mantenimiento de una representación social son la objetivación y el anclaje (Moscovici, 1979 [1961], 1986; Jodelet, 1986; Ibáñez, 1988; Billig, 1993; Wagner y Hayes, 2005). Estos mecanismos explican cómo lo social transforma un conocimiento en representación y cómo esta cambia lo social. La objetivación es el proceso de transformar información abstracta en conocimiento concreto, a través de la comunicación, que culmina con la creación de significados figurativos, metafóricos o simbólicos compartidos en distintos grados. Este proceso de objetivación implica otros como la selección, la esquematización y la naturalización. El anclaje, por otra parte, consiste en la incorporación de los eventos, acontecimientos, significados extraños a categorías y nociones familiares dentro de un grupo social específico. Este proceso de anclaje depende de la difusión de conocimientos y creencias en diferentes grupos sociales (Clémence, 2001; para una descripción más detallada ver Jodelet, 1986).

A partir del estudio de los mecanismos de la objetivación y el anclaje, la teoría se ha abocado a comprender las actividades simbólicas que configuran las personas para incorporar lo extraño a lo familiar. Sin embargo, como lo señala Michael Billig (1991), es importante considerar también el proceso contrario: la trascendentalización, esto es, hacer abstracciones de lo concreto, revestir de simbolismos objetos concretos. Con esto se 
plantea que lo que genéricamente se denomina como lo extraño no es la única fuente de configuración de representaciones, sino que la religión y otros universos simbólicos que se caracterizan por trascendentalizar algunos aspectos del mundo y de la vida social siguen siendo fuentes importantes para el conocimiento ordinario (idem).

\section{LA COMUNICACIÓN, LA CULTURA \\ Y LAS REPRESENTACIONES SOCIALES}

La comunicación es el elemento fundamental para el mantenimiento, la elaboración y la transformación de la cultura. Es el medio a través del cual se construyen, reconfiguran y debaten los significados y los sentidos sociales. Pero, también, tiene su soporte en la cultura; sin ella las expresiones de los sujetos no tendrían un marco de interpretación y de entendimiento. La cultura, por su parte, es una estructura de sentido que se materializa en sistemas de creencias, valores compartidos y en producciones materiales de diversa índole. En términos generales, se puede decir que la comunicación es la cultura puesta en acción, que es la comunicación objetivada. Según Fuentes: (2004:39)

La comunicación es un factor constitutivo de lo humano: estamos hechos de comunicación, como individuos y como sociedades, pero también la usamos para afectar particularmente esta constitución.

La comunicación, entonces, es tanto una condición para la acción, como una acción en sí misma que afecta las relaciones interpersonales y societales.

La teoría de las RS ha señalado la importancia de compartir representaciones para hacer posible la comunicación:

Partiendo de la observación de que cada uno de nosotros tiene representaciones múltiples y ambiguas, si la persona quiere comunicar tiene que ajustarse a otro. Los miembros de grupos saben que están hablando de la misma cosa y hablando entre ellos. ¿Qué podrán decir?, sin representaciones sociales, la existencia de representaciones individuales serían inciertas y de corta duración (...) y la comunicación sería azarosa (Moscovici, 2001:25). 
Las RS son resultado de procesos comunicativos y socioculturales. El sentido común es un modo de conocimiento y de producción de sentido que, junto con otras formas de conocimiento, científicas, mágicas, míticas, etc., sirven para constituir realidades consensuales (Jodelet, 2007a). Pero para que se produzca un intercambio verbal entre agentes sociales se requiere mucho más que la utilización de un mismo código lingüístico: es indispensable que se compartan RS, que operen como un trasfondo común, necesario, incluso, para expresar divergencias. Como lo plantea Ibáñez (1988:53):

Este trasfondo común suple el estricto rigor discursivo necesario para transmitir sin ambigüedades los significados adecuados, rigor que es obviamente imposible mantener en las improvisaciones espontáneas de la vida cotidiana.

No obstante que la teoría de las RS surgió a partir de un estudio basado tanto en una encuesta a grupos poblacionales como en el análisis de contenido de la prensa escrita francesa (Moscovici, 1979 [1961]), ha sido mucho más utilizada para analizar cómo piensan los grupos sociales determinados objetos, y por esta razón el desarrollo metodológico de la teoría involucra métodos de asociación de palabras, cuestionarios y análisis estadístico, o, en su caso, entrevistas, etnografía, historias de vida y análisis de contenido o del discurso. Se trata de múltiples investigaciones encaminadas a desentrañar cómo el pensamiento de sentido común enfrenta diversos aspectos de la realidad.

De modo que es posible puntualizar que cuando se estudia la RS de algo se está estudiando principalmente: a) lo que piensan los sujetos, llámese, producto, imagen o contenido con referencia a un objeto; b) cómo los sujetos piensan el objeto, cómo lo construyen y lo utilizan, es decir, los procesos cognitivos y comunicativos (colectivos de pensamiento e intercambio social) que elaboran ese contenido, lo crean y lo transforman; c) por qué los sujetos lo piensan o lo expresan de una manera determinada, esto es, cuáles son las funciones prácticas y comunicativas, y sus confrontaciones en la elaboración de una realidad común (Gaffié, 2005).

Sin embargo, también sería posible estudiar cómo un medio de comunicación, como instancia privilegiada del espacio público, hace 
circular representaciones sociales que constituyen fuentes de influencia o negociación en los grupos o comunidades locales. Como dice Farr (1986:496):

A menudo escuchamos que el arte de la conversación está moribundo y que los responsables de ellos son los mass media. Esto equivale a olvidar que es precisamente la comunicación de masas la que al reflejar, crear y transformar las representaciones sociales, ordena la forma y el contenido de las conversaciones. Numerosas representaciones son sociales porque son transmitidas por los medios de comunicación. Esta relación ilustra todo el interés que tiene el análisis del contenido de los medios de comunicación para el estudio de las representaciones sociales.

\section{LAS REPRESENTACIONES SOCIALES \\ Y LA COMUNICACIÓN MEDIÁTICA}

Para desarrollar su teoría, Moscovici desarrolló algunos conceptos que pueden ofrecer contribuciones significativas para los trabajos sobre mass media, como sus procesos formadores (anclaje y objetivación), los principios de transformación de lo extraño en algo familiar, los sistemas de comunicación de la difusión, la propagación y la propaganda, así como la idea de que son al mismo tiempo productos sociales y partes del proceso de construcción de la realidad (Nantes, 2004). La mayor parte de estos conceptos ya han sido abordados líneas atrás, con excepción de los sistemas de comunicación. Por este motivo este apartado del artículo se centrará en exponer la importancia que estos tienen para la formación de RS y, en especial, los hallazgos de Moscovici respecto a los sistemas de comunicación de la difusión, la propagación y la propaganda. ${ }^{6}$

Las RS son expresiones del pensamiento de sentido común que, sobre la base de hacer familiar lo extraño -incorporar las novedades-, sirven a la comprensión del cambiante mundo moderno. En este sentido, como formula Moscovici y algunos de sus seguidores (1986), las RS

6 Algunas reflexiones interesantes con respecto a estos tres sistemas de comunicación se encuentran en Valencia (2007). 
son producto de la era moderna, surgimiento favorecido por el desarrollo de la ciencia y por los procesos de difusión de que es objeto a través de los medios de comunicación.

Estos, al convertirse en asiduos divulgadores de la ciencia, han imprimido una nueva forma al sentido común. Los contenidos de la ciencia, a través de su difusión en las industrias de medios, han conformado un sentido común que adapta sus presupuestos, incorporando las novedades que las ciencias configuran para dar cuenta del mundo físico, social y psicológico (ver Moscovici, 1986).

En tanto los medios de comunicación son fuentes inagotables de incorporación de elementos novedosos o extraños a la vida social, ponen a disposición de los individuos lenguajes, nociones e imágenes que la ciencia (entre otras instancias de significación) ha venido inventado para entender la realidad. El pensamiento de sentido común no permanece ajeno a estas influencias: recupera estos lenguajes, nociones e imágenes y los incorpora de forma activa en la modalidad de RS.

Los medios de comunicación, entre muchas otras manifestaciones materiales de la cultura, hacen circular significados a los que acceden determinados grupos sociales como fuentes de información, a los cuales se asigna un sentido propio. La circulación abundante y constante de informaciones parciales, contradictorias o contrastantes en las sociedades contemporáneas impele a los actores sociales a pronunciarse sobre objetos más o menos desconocidos. Como lo plantea Moliner (1996), estas circunstancias obligan a la gente a demostrar su capacidad de actuar, tomar partido, responder, y para ello surgirán RS, cuya creación está siendo estimulada por múltiples debates mediáticos. De la misma manera como la ubicación social de un grupo determinará su interés particular por ciertos aspectos y su desinterés por otros sobre el objeto de representación (idem), las percepciones de los agentes de los medios sobre las audiencias de tal o cual producto mediático implicará una selección similar de ciertos aspectos sobre otros.

La difusión continua de ideas y opiniones a través de los medios de comunicación masiva ha gestado un sentido común capaz de expresarse, combinando de forma creativa lo experto y lo cotidiano. Numerosas representaciones son sociales porque son transmitidas por los medios de comunicación: 
Nos encontramos ante representaciones sociales cuando los individuos debaten temas de mutuo interés - por otra parte un gran número de conversaciones abordan temas metafísicos o existenciales- o cuando se hace eco de los acontecimientos seleccionados como significativos o dignos de interés por quienes controlan los medios de comunicación (Farr, 1986).

Las RS serían tanto el resultado de los procesos comunicativos que emergen de las instituciones mediáticas como de aquellos que surgen en las interacciones sociales cotidianas. En ambos casos, las RS son productos socioculturales, estructuras significantes que emanan de la sociedad y que nos informan sobre sus características (Ibáñez, 1988).

Sin embargo, el concepto y la teoría de las RS han sido menos utilizados para estudiar productos mediáticos, la publicidad, la prensa escrita, los noticieros o los programas de ficción televisiva, y el propio Moscovici juzga conveniente el uso de la teoría para el análisis de productos culturales, como los mediáticos y los artísticos, o incluso, los científicos:

Una teoría de la representación no trata únicamente con el hombre o la mujer de carne y hueso. Nos permitiría entender los trabajos creados conjuntamente, y más allá de eso, la literatura, novelas, cine, arte, cualquier ciencia y las instituciones que les dan forma objetiva. ¿No está ahí un gran almacén de material relacionado con nuestra habilidad para adquirir conocimiento y para comunicar y ser encontrado en diversos dominios culturales? (Moscovici, 2003 [1988]:111).

En este sentido, es importante comprender que si bien las RS implican la red de creencias e imágenes que emergen en el marco de una comunidad cultural local, o un grupo social específico, también circulan en una esfera transubjetiva, ${ }^{7}$ la del espacio público y social.

7 Denise Jodelet (2007b) ha propuesto considerar tres esferas de referencia de las RS: a) la esfera de la subjetividad, que nos sitúa en los procesos a través de los cuales el sujeto se apropia y construye representaciones en conexión con sus experiencias y vivencias individuales; b) la esfera de la intersubjetividad, en la que las representaciones son construidas en la interacción entre 


\section{EN LOS ESTUDIOS SOBRE EL MENSAJE}

Los fenómenos de comunicación mediática, especialmente de divulgación de la ciencia, han marcado, desde sus inicios, el desarrollo de la teoría de las RS. Esta teoría surgió como resultado de una investigación empírica sobre la difusión del psicoanálisis en el público francés. Ahí Moscovici estudió las ideas de los franceses de los años cincuenta con respecto al psicoanálisis (mediante encuestas), y analizó el contenido de artículos de prensa que versaban sobre aquel. De esta manera pudo confrontar la opinión pública y la de organismos de prensa con la del público y las expresadas en relaciones de interacción (1979 [1961]). En este último aspecto encontró que el psicoanálisis era considerado en la prensa escrita bajo tres modalidades de comunicación: 1) la difusión, enfocada a generar opiniones, a crear algún conocimiento común, adaptándose a los intereses de su público; 2) la propagación, destinada a generar actitudes y propiciada por un grupo social que hiciera prevalecer una visión del mundo organizada en la que tuvieran cabida nuevos saberes (p.ej. los textos de la Iglesia intentaban acomodar el saber psicoanalítico a los principios

individuos, a través de la comunicación verbal y la negociación de sentidos en un grupo o comunidad local, y c) la esfera transubjetiva, que se refiere al espacio social y público donde circulan representaciones que cruzan los espacios locales de vida. En cada una de estas esferas, las RS cumplen distintas funciones: en la esfera de lo subjetivo, las RS "tienen una función expresiva, permiten ver los significados que los sujetos conceden a un objeto localizado en su entorno social y físico, a partir de sus sensibilidades, intereses, deseos." En la esfera de lo intersubjetivo, las RS “intervienen como medios de comprensión, herramientas de las interpretaciones y de la construcción de significados compartidos acerca de los objetos de negociación." Mientras que la esfera transubjetiva, "corresponde al aparato cultural, al conjunto de modelos, normas y valores transmitidos socialmente, así como al universo simbólico correspondiente a las presiones que imponen la estructura social y de poder, y las ideologías. A tal nivel, el sistema de representación ofrece los criterios de codificación y de clasificación de la realidad, suministra los instrumentos mentales, los repertorios que permiten construir las significaciones compartidas en la sociedad. 
religiosos); y 3) la propaganda, concerniente al nivel de los estereotipos, que expresaría las dinámicas comunicativas que se inscriben en relaciones sociales conflictivas y favorecería procesos de categorización dicotómicos (p.ej. los textos de la prensa comunista presentaban al psicoanálisis como un instrumento político de la burguesía).

La investigación de Moscovici (1979 [1961]) identificó que estos tres sistemas de comunicación determinaban la forma y el contenido de los mensajes emitidos y recibidos en la prensa escrita sobre el psicoanálisis. Encontró que cada sistema de comunicación fomentaba ciertos modelos cognitivos y lingüísticos, así como determinados estilos comunicativos. La difusión, según el planteamiento de Moscovici, se caracteriza por realizarse en un "estilo concreto, atrayente, rápido", por el uso recurrente de "proposiciones sorprendentes", por la transmisión de contenidos discontinuos, segmentados, aleatorios o poco sistemáticos, por manifestar distancia -no compromiso o escasa implicación- con respecto al objeto de referencia, por estar justificadas apelando a especialistas. El propósito de esta forma de comunicación es generar opiniones que agraden al público; un público masivo, diverso, amplio, versátil. La propagación, por su parte, implica "la transmisión de mensajes estructurados y explícitos que poseen como fundamento un marco de referencia que se expresa claramente..." (ibidem: 267). Este sistema de comunicación contempla publicaciones cuyo papel es fomentar y preparar mensajes que posean una organización explícita y más o menos clara para que puedan ser retomados y retransmitidos (p. ej. la prensa católica). En este caso, la fuente "goza de autonomía relativa y se encuentra investida de una autoridad innegable" (ibidem: 281). Y finalmente la propaganda, que es una forma de comunicación cercana a la propagación, pues se caracteriza por el uso de modelos sistemáticos y por conllevar altas cargas de implicación (p. ej. la prensa comunista). Sin embargo, como escribe Moscovici:

La propaganda es más concreta, no se contenta con renovar la significación de un comportamiento sino que tiende a crearlo o reforzarlo. El universo está estrictamente dicotomizado; la situación que la suscita es diferente. Los estereotipos corrientemente utilizados circunscriben el universo afectivo de una manera particular (idem). 
La propaganda lleva al extremo el fomento, refuerzo y creación de ciertos significados que deben ser asociados a un objeto; las ideas se repiten con altas cargas de simplificación y a partir de una sistematización dicotómica.

Esta caracterización sobre los sistemas de comunicación y los hallazgos sobre la difusión del psicoanálisis son un punto de partida interesante para pensar la relación entre formas de comunicación mediática y la circulación de RS en la esfera pública. Cabe remarcar que son un punto de partida solamente, pues se trata de una tipología creada exclusivamente para el análisis de la prensa escrita en un contexto muy distinto al actual, en cuanto a la emergencia de formas de comunicación masiva y nuevas tecnologías de información, así como ante la hibridación de géneros comunicativos. Las nuevas tecnologías han transformado los circuitos de difusión de la cultura y, en consecuencia, la circulación, permanencia o cambio de las RS. El acceso a los medios de comunicación masiva era una posibilidad exclusiva de gobiernos, empresas y organizaciones, mientras que, en la actualidad, con la emergencia de las tecnologías digitales, la proliferación de computadoras personales y servicios de Internet se facilita cada vez más la difusión masiva de ideas a los ciudadanos (p. ej. a través de los blogs, wikis, etc.). Asimismo, los géneros de la difusión, la propagación y la propaganda suelen fusionarse con mucha frecuencia, como en los casos en que la publicidad (o la propaganda política) se disfraza de información o entretenimiento, o la difusión y la propagación se acompañan de "goles publicitarios". Estos nuevos escenarios de la comunicación mediática, y otros más que no es posible señalar aquí, no deben pasar desapercibidos por quienes retomen el camino diseñado por Moscovici para comprender las interrelaciones entre RS y sistemas de comunicación. No obstante, el valor de estas aportaciones se mantiene porque invitan a pensar que las RS, en cuanto a forma y contenido, cambian en función de la modalidad principal de comunicación en la que circulan en los medios de comunicación y porque llaman la atención sobre la importancia de la comparación entre distintas modalidades de comunicación en estrecha conexión con grupos y relaciones sociales más o menos en conflicto.

Los profesionales de los medios de comunicación y de mercadeo político constituyen una de esas categorías de personas cuya profe- 
sión contribuye para la reproducción o transformación de RS, pues difuminan conocimiento artístico, científico y cultural y ocupan el papel de "modernos equivalentes de los hacedores de mitos de las sociedades antiguas" (Moscovici, 2003 [1988]:85). Los resultados compilados por Ghiglione y Trognon (1993) muestran que un locutor experto dentro de un dominio construye discursos diferentes según se vaya a informar a pares (expertos), estudiantes o el gran público: el contrato de comunicación iniciado por el locutor está entonces determinado por su representación del destinatario (citados por Gruev-Vintila, 2001). Pero aun así es obvio que las actividades particulares de los grupos de profesionales ${ }^{8}$ que producen los contenidos mediáticos no son actos completamente racionalizados y calculados, sino que también exteriorizan los hábitos del sistema cultural que constituye el sentido común, esa red de imágenes y significados aprendidos en el marco de una situación histórica determinada y de la pertenencia a determinados grupos sociales, aunque por supuesto también intervienen los conocimientos especializados, de carácter profesional, así como ideológicos o políticos.

Los productos mediáticos tienden a reconstruir las RS de las audiencias a las que se dirigen, de manera que los públicos se sientan identificados con dichos productos y los consuman, aunque también, probablemente, introducen nuevos elementos (resultado de la interacción entre conocimientos de sentido común y saberes especializados) que pueden contribuir a su transformación. Los medios de comunicación son, así, tanto una fuente de reproducción como de innovación cultural que bien pueden influenciar, si bien no de un modo determinante, las prácticas identitarias y las RS de los grupos sociales.

Rouquette (citado en Moscovici, 1988:499-500) menciona que no sólo hay interpretación en el interior de los individuos, y yo agregaría

8 Estos grupos profesionales constituyen un caso en que sus miembros comparten acervos comunes sobre teorías concernientes a su campo y a la socialización profesional, pero que no se comunican regularmente cara a cara en conversaciones. Sin embargo, comparten representaciones sociales que, se puede suponer, tienen importantes efectos sociales en el manejo de objetos y problemas en la sociedad (Flick, 1993). 
de los grupos sociales, que reciben informaciones, sino que estas ya vienen con "sesgos" de interpretación. Esta idea la desarrolla el creador de la teoría de la siguiente manera:

Los medios de comunicación tienen la peculiaridad de transformar la información proveniente de otras fuentes para alcanzar una gran audiencia: "La gramática debe ser alterada, la trayectoria lógica acortada, las palabras cambiadas en imágenes, las ideas en metáforas, si el contenido quiere ser retomado y entendido" (Wade y Schram, 1969). La misma cosa pasa cuando un especialista le habla a una audiencia de no-especialistas, un profesor a sus estudiantes y un doctor a sus pacientes. De la misma manera, el texto de un artículo es elaborado y escrito diferencialmente para la lectura, para una entrevista o para un tema de conversación con los colegas. Este estilo es alterado, así como el razonamiento, los ejemplos y la naturaleza de las conclusiones a que se llegue (Moscovici, 2003 [1988]:72).

Estudiar esos sesgos de las interpretaciones mediáticas podría ser un campo de estudio fértil para la teoría de las RS. Se podría estudiar cómo la lógica mediática, bajo determinadas modalidades, se impone en la elaboración de las RS que circulan por estos canales de comunicación y que se construyen a través de la selección de hechos, difusión de creencias atrayentes, más o menos simplificadas, dramatizadas a partir de narrativas y, comúnmente, sin matices y descontextualizadas.

Los medios de comunicación, como instancias privilegiadas del espacio público, constituyen una esfera de manifestación de RS. Estas, no obstante, operan en una escala superior a la subjetividad y a la interacción social en comunidades locales, es decir, circulan en una escala transubjetiva (ver Jodelet, 2007b).

La discusión que he presentado me permite afirmar que cuando se estudian las RS en la cultura mediática -los mensajes- se está estudiando cómo una entidad del espacio público proyecta una visión de un objeto social (su papel como generadora de imágenes culturales), cómo se objetivan saberes especializados divulgados o aplicados (sean mercadotécnicos, científicos, religiosos, políticos) en sus productos (focalización selectiva, asignación de sentido, etc.) y cómo se anclan con saberes preexistentes generados en otras instancias de socialización y 
que forman parte del sentido común de determinadas categorías sociales; cómo la modalidad de comunicación mediática en que circulan determinados mensajes afecta el contenido y la forma de la representación social sobre un objeto dado, y finalmente, cuáles son los grupos sociales que contienden fomentando, reforzando o creando RS en el espacio de los medios de comunicación.

\section{CONSIDERACIONES FINALES}

¿Qué podría aportar la teoría de las RS a las investigaciones sobre el mensaje? Para continuar respondiendo esta pregunta de manera concreta, pensemos por un momento en los estudios sobre cómo un medio representa un grupo social. ${ }^{9}$ Estos estudios suelen recurrir con frecuencia a los conceptos de estereotipos y sesgos (Giles, 2003; Williams, 2003), si bien hay múltiples investigaciones que proponen abordajes más complejos desde la semiótica, el análisis del discurso, las narrativas, etc. Sin embargo, la representación de tales grupos no solamente contempla estas estructuras de conocimiento cotidiano. Desde la perspectiva de las RS, los estereotipos son expresiones esenciales o sintetizadas de las expresiones y componentes de una representación social (Moliner, 1996). El concepto de RS es un concepto alternativo que se podría sumar a los que ya han sido propuestos como fuentes teóricas para comprender la selección y organización de los materiales que produce la comunicación mediática. ${ }^{10} \mathrm{La}$ idea de que una representación social es un sistema holístico en el que se integran y jerarquizan diversas clases de cogniciones, permitiría analizar cómo están conformados los productos mediáticos, considerando no solamente el conocimiento cotidiano que se expresa en estereotipos, sino

9 "Muchas de estas investigaciones concluyen que el entretenimiento y las noticias mediáticas no reflejan la diversidad real del mundo, pues con frecuencia son subrepresentados o malpresentados ciertos grupos sociales; así mismo se sostiene que los medios reflejan y afianzan los patrones existentes de desigualdad económica y social" (Tunstall, citado por Gripsrud, 2002: 5).

10 Una discusión de estos conceptos se encuentra en Alvarado et al. 1987 (citado por Giles, 2003) y Williams, 2003. 
también en ideales, valores, metáforas, casos ejemplares y otros tipos de cogniciones que actúan de manera interrelacionada y jerárquica. Esto implicaría identificar cómo distintas clases de cogniciones se organizan mutuamente, esto es, cómo cada pieza y fragmento (signos y significados) se une con otros para generar una representación social. En este punto conviene recordar que la idea de RS no remite a un cajón donde se amontonan contenidos, sino a una estructura de relaciones y jerarquías de significación (Ibáñez, 1988).

Para investigar cómo los medios de comunicación distribuyen prejuicios sobre ciertos grupos sociales o sistemas de conocimientos sobre otros objetos culturales y sociales, es posible considerar los avances de la teoría de las RS: posibilitaría comprender de manera más precisa, interrelacionada, cómo los productos mediáticos construyen versiones sobre la realidad y las negocian socialmente. Esto implica no solamente atender los conocimientos de sentido común que se comparten, sino también los diferentes matices con que circula la representación social sobre un objeto dado en tal o cual medio, o en tal o cual formato de comunicación. Se trata, entonces, de comprender las RS de manera dinámica, asumiendo que "están compuestas de significados diferentes, clases contrastantes de significados" (Clémence, 2001:85-86) y que comúnmente los contenidos centrales en una RS tienen un carácter polisémico (Moliner, 2007). Los textos mediáticos, como cualquier otro texto, están abiertos a un rango amplio y diferente de significados. El término polisémico se refiere a la noción de que cualquier mensaje puede tener una variedad de interpretaciones o, dicho en el lenguaje del análisis narrativo y el análisis de género, puede tener un rango de posibles lecturas. Sin embargo, esto suscita la pregunta sobre si hay lecturas preferidas incorporadas en el texto. El análisis del contenido mediático constituye como resultado un recurso necesario para comprender no sólo cómo se dicen las cosas sino también cómo son interpretadas (Williams, 2003).

No obstante, para analizar el conocimiento que se manifiesta en productos mediáticos, se requerirá, en muchos casos, otorgar mayor importancia a la imagen que al discurso. Para de Rosa (2001b), en la literatura sobre RS ha prevalecido un centralismo verbal que ha conducido a minusvalorar las imágenes y a sobrevalorar las palabras como sistemas de 
comunicación. Como tales, ambos sistemas de comunicación deberían estar considerados como canales específicos de génesis, transmisión y objetivación de RS:11

Sobre la base de las consideraciones anteriores, la imagen puede ser considerada al mismo tiempo como: una fuente que activa representaciones sociales o favorece el desarrollo de nuevas representaciones sociales, un producto de representaciones sociales, p.ej. una síntesis icónico-simbólica, una materialización condensada de una representaciones social, una expresión directa del proceso de objetivación, en otros términos como una representación social en sí misma. Un medio, una forma específica de transmisión, vinculada con canales diferenciados (tradicionalmente, las artes visuales, pero también la televisión, el cine, la fotografía, las nuevas tecnologías audiovisuales, Internet, etc.), a través del cual representaciones sociales, nuevas o preexistentes, son comunicadas (De Rosa, 2001b).

Las imágenes están siempre presentes en las comunicaciones mediáticas y participan de manera activa en la construcción de representaciones en la medida en que focalizan la atención sobre ciertos elementos del discurso. En este sentido, las imágenes pueden ser consideradas como un producto de las RS (ver Moliner, 1996).

Dejaré hasta aquí las reflexiones teóricas sobre los posibles usos de la teoría de las RS en el campo de la comunicación. Solamente reflexioné en lo que concierne al análisis de los mensajes mediáticos; sin embargo, otros autores (Yépez, 2004) han encontrado que esta teoría puede ser útil en los estudios sobre recepción. De hecho, la noción de "sociedad pensante" que fundamenta la teoría de las RS destaca las capacidades de los actores sociales para pensar y construir realidades. Esta visión sobre las capacidades constructivas del pensamiento de sentido común coincide con la de los teóricos de la recepción que han mostrado cómo la comunicación interpersonal y los grupos de referencia

11 Un estudio sobre la publicidad de Benetton (De Rosa, 2001a), una empresa de origen italiano dedicada a la moda que ha impulsado campañas de publicidad crítica, ha mostrado que los conceptos de objetivación y anclaje pueden explicar el éxito de este tipo de publicidad. 
generan categorías para dar sentido propio (ignorar, rechazar, apropiar, transformar) a los mensajes mediáticos.

\section{Bibliografía}

BILLIG, Michael (1993) "Studyng the thinking society: social representations, rhetoric, and attitudes", en Empirical approaches to social representations, editado por Glynis Breakwell y David Cantes. Oxford: Clarendor Press.

- (1991) Ideology and opinions. Studies in rethorical psychology. Londres: Sage.

CLÉMENCE, Alain (2001) "Social positioning and social representations", en Representations of the social, editado por Kay Deaux y Gina Philogène. Oxford: Blackwell.

DE RosA, Annamaria (2001a) "The king is naked. Critical advertisement and fashion: The Benetton phenomenon", en Representations of the social, pp. 48-82, editado por Kay Deaux y Gina Philogène. Oxford: Blackwell.

- (2001b) "Icon and symbol: two sides of the coin in the investigation of social representations", en Penser la vie, le social, la natura. Mélanges en homage à Serge Moscovici, pp. 237-256, editado por F. Buschini y N. Kalampalikis. Paris: Les Editions de la Maison des Sciences de l'Homme.

DOISE, Willem (1993) "Debating social representations", en Empirical Approaches to Social Representations, pp. 157-170, editado por G.M. Breakwell y D.V. Canter.

- (1991) "Las representaciones sociales: presentación de un campo de investigación, en Anthropos, 27. Barcelona.

FARR, Robert M. (1986) “Las representaciones sociales”, en: Psicología social, II, Serge Moscovici (comp.). Barcelona: Paidós.

FLICK, Uwe (1993) "Delightful representations of the paradoxes in the social world: discussion of M.J. Spink", en Papers on social representations, vol. 2, núm 1, pp. 60-65.

FUENTES, Raúl (2004) 'La producción social de sentido sobre la producción social de sentido: una propuesta de re-conocimiento para el campo de estudios de la comunicación", en Producción, circulación y reproducción académicas en el campo de la comunicación en México, coordinado por Raúl Fuentes. Guadalajara: ITESO. 
- (2003) "Estructuras de significación y procesos de comunicación. Modelos de integración teórica-metodológica desde una perspectiva sociocultural", en El laberinto de la cultura. Estudios de semiótica. Guadalajara: Universidad de Guadalajara, Centro de Arte, Arquitectura y Diseño.

GAFFIÉ, Bernard (2005) "Confrontations des Représentations Sociales et construction de la realité", Conferencia presentada el 19 de mayo de 2004. Disponible en: http://www.geirso.uqam.ca/jirso/Vol2_ Aout05/06Gaffie.pdf.

GARCíA P., José Gil (2004) "Sistemas de comunicación y representaciones sociales" en Representaciones sociales: Atisbos y Cavilaciones del devenir de cuatro décadas, editado por Eulogio Romero Rodríguez. México: Universidad Autónoma de Puebla.

GILES, David (2003) Media psychology. Mahwah, New Jersey: Lawrence Erlbaum.

GRIPSRUD, Jostein (2002) Understanding media culture. Oxford: Oxford University Press Gruev-Vintila, Andreea. 2001. "Représentations et communications sociales. Réflexion sur une mise en présence des modèles théoriques actuels". París 8-UQAM. Disponible en: http://www. memoires-theses.com/psychologie/representations-sociales-2.htm.

IBAÑEZ, Tomás (1988) Ideologías de la vida cotidiana. Barcelona: Sendai.

JODELET, Denise (2007a) "Hacia una psicosociología del sentido. Una integración de las ciencias sociales y la hermeneútica a partir del imaginario", conferencia presentada en el marco de la entrega del Doctorado Honoris Causa a Denise Jodelet en la Universidad de Guadalajara, Guadalajara, 9 de marzo de 2007.

- (2007b) Imbricaciones entre representaciones sociales e intervención, en Representaciones sociales. Teoría e investigación, coordinado por Tania Rodríguez y María de Lourdes García. Guadalajara: Universidad de Guadalajara.

- (1986) "La representación social: fenómeno, concepto y teoría", en Psicología Social II, editado por Serge Moscovici. Barcelona: Paidós.

MOLINER, Pascal (2007) "La teoría del núcleo matriz de las representaciones sociales", en Representaciones sociales. Teoría e investiga- 
ción, coordinado por Tania Rodríguez y María de Lourdes García. Guadalajara: Universidad de Guadalajara.

- (1996) Images et représentations sociales. Grenoble: Presses Universitaires de Grenoble.

MosCOVICI, Serge (2003) [1988]. "Notas hacia una descripción de la representación social", en: Psic. Soc. Revista Internacional de Psicología Social, vol. 1, núm. 2, enero-junio, pp. 67-118. [originalmente publicado en 1988, "Notes towards a description of social representations", en European Journal of Social Psychology, vol. 18, pp. 211-250.

- (2001) "Why a theory of social representations?", en Representations of the social, editado por Kay Deaux y Gina Philogène. Oxford: Blackwell.

- (1997) "Social Representations Theory and Social Constructionism”, participación en Social Representations mailing list. Disponible en: http://psyberlink.flogiston.ru/internet/bits/mosc1.htm.

- (1988) "Notes towards a description of social representations", en European Journal of Social Psychology, vol. 18, pp. 211-250.

- (1986) “De la ciencia al sentido común”, en Psicología Social II. Barcelona: Paidós.

— (1979 [1961]) El psicoanálisis, su imagen y su público. Buenos Aires: Huemul.

NANTES P., Rosana (2004) “Teoria das Representações Sociais: pertinência para as pesquisas em Comunicação de Massa”, en Comunicação e Espaço Público, año VII, núm. 1, pp. 128-141.

RODRÍGUEZ, Tania (2007) "Sobre el estudio cualitativo de la estructura de las representaciones sociales" en Representaciones sociales. Teoría e investigación, coordinado por Tania Rodríguez y María de Lourdes García. Guadalajara: Universidad de Guadalajara.

ROUQUETTE, Michel-Louis (1996) Social representations and mass communication research, en: Journal for the theory of social behaviour, vol. 26, núm. 2, pp. 221-231.

VALENCIA, Silvia (2007) "Elementos de la construcción, circulación y aplicación de las representaciones sociales", en Representaciones sociales. Teoría e investigación, coordinado por Tania Rodríguez y María de Lourdes García. Guadalajara: Universidad de Guadalajara. 
WAGNER, Wolfgang y Nicky Hayes (2005) Everyday discourse and common sense. The theory of social representations. Houndmills: Palgrave.

- y Fran Elejabarrieta (1994) Representaciones sociales, en Psicología social, editado por J. Francisco Morales. Madrid: UNED-McGrawHill.

WILLIAMS, Kevin (2003) Understandig media theory. Londres: Arnold

YÉPEZ Hernán, Margarita (2004) "Estudio de los efectos de los mensajes de los medios desde las representaciones sociales", en Hacia la construcción de una Ciencia de la Comunicación en México. Ejercicio reflexivo 1979-2004, coordinado por Lenin Martell. México: Asociación Mexicana de Investigadores de la Comunicación (AMIC). 